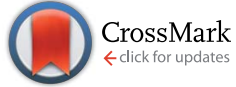

Cite this: RSC Adv., 2017, 7, 10494

Received 20th December 2016 Accepted 1st February 2017

DOI: $10.1039 / c 6 r a 28473 f$

rsc.li/rsc-advances

\section{Stepwise co-sensitization of two metal-based sensitizers: probing their competitive adsorption for improving the photovoltaic performance of dye-sensitized solar cells $\dagger$}

\begin{abstract}
Yanming Zhao, ${ }^{\text {ab }}$ Futai Lu, ${ }^{a}$ Jie Zhang, ${ }^{c}$ Yuze Dong, ${ }^{a}$ Bao Zhang ${ }^{\star a}$ and Yaqing Feng*ab
How to graft co-sensitizers with different binding strengths onto $\mathrm{TiO}_{2}$ surfaces for enhancing the performance of dye-sensitized solar cells (DSSCs) has not been discussed very much. Herein a ruthenium-based sensitizer (N719) and a porphyrin molecule (LP-2) with complementary absorption spectra $(300-750 \mathrm{~nm}$ ) have been chosen to investigate how the dye loading procedure would influence the photovoltaic performance of co-sensitized solar cells. Interestingly, it is found that $54.7 \%$ of the loading amounts of pre-adsorbed LP-2 are replaced by the post-adsorption of N719. The replacement adsorption is not observed when the two molecules are loaded in reverse order, which is attributed to their different adsorption configurations and binding energies. The competitive adsorption between cosensitizers is thus systematically investigated by UV-visible absorption spectroscopy, energy dispersive spectrometry (EDS) and electron probe microanalysis (EPMA). Upon optimization, the device sequentially sensitized with LP-2 and N719 exhibits efficiency (7.72\%) enhancement of $38.6 \%$ and $18.0 \%$ compared with those fabricated with single LP-2 and N719, respectively. The results provide a new vision on the stepwise sensitization of $\mathrm{TiO}_{2}$ films using co-sensitizers with a difference in adsorption properties, suggesting that complementary spectral absorption of co-sensitizers can lead to excellent cell performance by choosing an appropriate dye loading procedure.
\end{abstract}

\section{Introduction}

As the third generation of photovoltaic devices utilizing sunlight, dye-sensitized solar cells (DSSCs) have attracted considerable attention in recent years due to their relatively low cost, easyfabrication process and high photo-to-electron conversion efficiency (PCE). ${ }^{1-3}$ In order to improve light-harvesting efficiencies of DSSCs, various types of sensitizers have been developed including ruthenium complexes, ${ }^{4-6}$ zinc porphyrins ${ }^{7-10}$ and metalfree organic dyes. ${ }^{11-16}$ To date, DSSCs based on zinc porphyrin (SM315) have attained the highest PCE of $13 \% .{ }^{17}$ However, designing and synthesizing a single dye molecule that can absorb panchromatic sunlight is still challenging, as it may involve complex reactions, purification procedures and high cost. Moreover, the HOMO and LUMO orbitals of the sensitizers may not match the energy levels of the electrolyte or the conduction

${ }^{a}$ School of Chemical Engineering and Technology, Tianjin University, 135, Yaguan Road, Jinnan District, Tianjin 300350, China. E-mail: baozhang@tju.edu.cn; yqfeng@tju.edu.cn; Fax: +86-022-27892323; Tel: +86-022-27892323

${ }^{b}$ Tianjin Co-Innovation Center of Chemical Science and Engineering, Tianjin 300072, China

${ }^{c}$ School of Science, Tianjin Chengjian University, Tianjin 300384, China

$\dagger$ Electronic supplementary information (ESI) available. See DOI: 10.1039/c6ra28473f band of the $\mathrm{TiO}_{2}$ electrode when the synthetic work has been completed. ${ }^{18-23}$ As a consequence, taking the absorption spectra and the light-harvesting efficiency into account, the cosensitization approach employing two or more dyes with complementary absorption spectra co-adsorbed on $\mathrm{TiO}_{2}$ films has generated promising results in DSSCs. ${ }^{24-33}$ For example, cosensitization of YD2-o-C8 with a D- $\pi-A$ organic dye (Y123) possessing the complementary absorption spectrum achieved incident photon-to-electron conversion efficiency (IPCE) of $>90 \%$ on the whole absorption spectra and boosted the cell device performance to the PCE of $12.3 \%$ in $2011,{ }^{34}$ which motivates further investigation on the co-sensitization in DSSCs. Ho et al. first reported the co-sensitization in plastic DSSCs with black dye/ FL and N719/FL at low temperature, which showed pronounced improvement in PCE. ${ }^{35}$ In 2014, Peng et al. used a zinc phthalocyanine (Zn-tri-PcNc-1) and a metal-free organic dye ( $\mathrm{DH}-44)$ as the co-sensitizers sequentially adsorbed on $\mathrm{TiO}_{2}$ films and the cosensitized cell device exhibited PCE (6.61\%) enhancement of $28.1 \%$ and $177.7 \%$ relative to those sensitized with the individual dyes. ${ }^{36}$ Likewise, Zhu et al. fabricated the cell device sensitized with a metal-based sensitizer (zinc porphyrin) and a metal-free organic dye. The PCE of $10.41 \%$ for the co-sensitized device was obtained. ${ }^{37}$ Wang et al. also investigated the co-sensitization effects on the performance of DSSCs by employing the zinc 
porphyrin and metal-free organic dye. ${ }^{38}$ As comparison, cosensitization using two pure organic sensitizers (IQ21 and S2) for the enhancement of photovoltaic performance was reported by Zhu's group. They found that the improved PCE (10.4\%) of the co-sensitized device far surpassed those of the devices sensitized with single dyes, which is attributed to the well-matched molecule structure and the loading amounts of the two dyes. ${ }^{39}$ Recently, Hu et al. synthesized the conjugated polyphenylene (7$\mathrm{BC})$, but the PCE of the device sensitized with 7-BC only reached $0.16 \%$. However, the DSSC co-sensitized with 7-BC and N719 showed a much higher PCE of $9.68 \%$ compared to the PCE $(8.34 \%)$ of the N719-based device due to the increase in light harvesting, and the retardation of electron recombination and dye aggregation. ${ }^{\mathbf{4 0}}$ The remarkably improved efficiency shows that co-sensitization is an effective approach for the enhancement of the photovoltaic performance of DSSCs.

It is noted that screening the co-sensitizers with well-matched molecular structures has gained extensive attentions, since it is widely accepted that the $\mathrm{TiO}_{2}$ surface can be sufficiently occupied by these sensitizers, dye aggregation effectively restrained and consequently, the improved light-harvesting efficiency and the reduced electron recombination realized. ${ }^{36-39,41-45}$ On the other hand, how to graft two dye molecules with different binding energies and adsorption modes onto $\mathrm{TiO}_{2}$ surfaces would certainly influence the performance of the resultant co-sensitized solar cells, since improper loading of two dye molecules to the $\mathrm{TiO}_{2}$ surface would lead to ineffective dye penetration into the inner of the $\mathrm{TiO}_{2}$ film, the imbalanced dye loading amounts, and thus the possible aggregation of the dye molecules on $\mathrm{TiO}_{2}$ films. The improved short-circuit current $\left(J_{\mathrm{sc}}\right)$ and open-circuit voltage $\left(V_{\text {oc }}\right)$ cannot be achieved. It is believed that stepwise sensitization of co-sensitizers with different binding energies and adsorption modes on $\mathrm{TiO}_{2}$ films may be an effective approach to enhance the DSSC performance via the competitive adsorption between the co-sensitizers. As a result, the $J_{\mathrm{sc}}$ can be improved based on the trade-off between the dye-loading amounts and the reduced aggregation to some extent. ${ }^{4-52}$

In this study, to further investigate the influence of the loading procedure for the co-sensitizers on the performance of DSSCs, we selected two metal-based sensitizers (a rutheniumbased sensitizer and a porphyrin molecule denoted as N719 and LP-2, respectively) with well complementary absorption spectra for the co-sensitized DSSCs. The Soret and Q absorption bands ${ }^{11}$ of LP-2 well compensate the weak absorption in the 400$500 \mathrm{~nm}$ and $600-700 \mathrm{~nm}$ regions for N719. ${ }^{5}$ Two co-sensitization procedures were discussed in detail, including the cocktail approach (using a mixture of dye solutions) and the stepwise approach (sequential loading of two dyes). The DSSC sequentially sensitized with LP-2 and N719 performs the best PCE. Interestingly, it is found that $54.7 \%$ of the LP-2-loading amounts is replaced by the post-adsorption of N719. To further understand the influence of the stepwise sensitization on the loading amounts of the two dyes, the results obtained from the stepwise sensitization via a different soaking order were compared. The competitive adsorption was systematically investigated by UVvisible absorption spectroscopy, energy dispersive spectrometer (EDS) and electron probe microanalysis (EPMA). The incident photon-to-electron conversion efficiency (IPCE) spectra and the electrochemical impedance spectroscopy (ESI) technique were also employed to elucidate the improved performance of the cosensitized DSSCs. Eventually, the co-sensitized device reached the highest PCE of $7.72 \%$, which is improved by $18.0 \%$ and $38.6 \%$ in comparison with those of the devices sensitized with single LP-2 and N719, respectively. The improved performance is ascribed to the complementary absorption spectra, the competitive adsorption ensuring the balance of the loading amounts of two sensitizers and the reduced aggregation of $\mathrm{LP}-2$ on $\mathrm{TiO}_{2}$ films. The study here provide a new vision on the stepwise sensitization of $\mathrm{TiO}_{2}$ films using co-sensitizers with different binding properties on $\mathrm{TiO}_{2}$ surfaces for the enhancement of the performance of co-sensitized solar cells.

\section{Experimental}

\subsection{Materials}

Fluorine-doped tin oxide substrate (FTO, sheet resistance $15 \Omega$ per square) was obtained from HeptaChroma. Other chemicals such as lithium iodide, iodine, 4-tert-butylpyridine (4-TBP) and 1,2-dimethyl-3-propylimidazoliumiodide (DMPII), were all purchased from the Shanghai Institute of Aladdin. The zinc porphyrin (LP-2) was synthesized according to the literature procedure, ${ }^{53}$ and N719 obtained from Solaronix, Switzerland. P25 was purchased from Degussa AG, Germany. And all the chemicals were used without further purification.

\subsection{Preparation of photoanode}

The $\mathrm{TiO}_{2}$ paste used for fabricating photoanode was prepared by mixing $1 \mathrm{~g} \mathrm{TiO}_{2}$ powder, $0.1 \mathrm{~g}$ lauric acid, $3.5 \mathrm{~g}$ terpilenol, $0.5 \mathrm{~g}$ ethyl cellulose and $50 \mathrm{~g}$ ethanol together. Then $30 \mathrm{~g}$ zirconium beads were added, and after ball-milling treatment for $4 \mathrm{~h}$, the mixture was concentrated using a rotary evaporator and grinded to form viscous paste. In addition, the FTO conducting glasses were ultrasonically cleaned with detergent solution, distilled water and ethanol for $30 \mathrm{~min}$ successively, then immersed in $50 \mathrm{mM}$ aqueous $\mathrm{TiCl}_{4}$ solution at $70{ }^{\circ} \mathrm{C}$ for $30 \mathrm{~min}$ and washed with water and ethanol subsequently. $\mathrm{TiO}_{2}$ films were prepared by using a doctor blade printing $\mathrm{TiO}_{2}$ paste on the precleaned FTO glass and dried at $70{ }^{\circ} \mathrm{C}$ for $30 \mathrm{~min}$. The $\mathrm{TiO}_{2}$ electrodes were heated under an air flow at $325{ }^{\circ} \mathrm{C}$ for $5 \mathrm{~min}$, at $375^{\circ} \mathrm{C}$ for $5 \mathrm{~min}$, at $450{ }^{\circ} \mathrm{C}$ for $15 \mathrm{~min}$, and at $500^{\circ} \mathrm{C}$ for $30 \mathrm{~min}$. After naturally cooled to room temperature, the $\mathrm{TiO}_{2}$ electrodes were treated with $50 \mathrm{mM}$ aqueous $\mathrm{TiCl}_{4}$ solution at $70{ }^{\circ} \mathrm{C}$ for $30 \mathrm{~min}$, rinsed with ethanol, and heated at $500{ }^{\circ} \mathrm{C}$ for 30 min. After cooled to $110{ }^{\circ} \mathrm{C}$, the $\mathrm{TiO}_{2}$ electrodes were immersed into the pre-made dye solutions. The individually dye-sensitized photoanode was prepared by immersing the $\mathrm{TiO}_{2}$ films in LP-2 (0.3 mM in ethanol/THF) or N719 (0.3 mM in ethanol) solution, and for the co-sensitized photoanode, the $\mathrm{TiO}_{2}$ film was dipped into the two single dye solutions in sequence or a solution of two mixed dyes and the soaking hour for $\mathrm{TiO}_{2}$ films into the dye solutions was further optimized through a series of experiments. 
Table 1 Photovoltaic parameters of DSSCs based on LP-2, N719 and co-sensitization of the two dyes measured under simulated AM 1.5 G solar light

\begin{tabular}{|c|c|c|c|c|c|c|}
\hline Device & Dye & $\Gamma^{a}\left(\mathrm{~mol} \mathrm{~cm}^{-2}\right)$ & $J_{\mathrm{sc}}\left(\mathrm{mA} \mathrm{cm} \mathrm{cm}^{-2}\right)$ & $V_{\mathrm{oc}}(\mathrm{mV})$ & $\mathrm{FF}(\%)$ & PCE (\%) \\
\hline 1 & $18 \mathrm{~h}$ in $\mathrm{N} 719$ & $1.33 \times 10^{-7}$ & $12.65 \pm 0.23$ & $779 \pm 4$ & $69.43 \pm 1.00$ & $6.54 \pm 0.07$ \\
\hline 2 & $3 \mathrm{~h}$ in LP-2 & $1.48 \times 10^{-7}$ & $11.09 \pm 0.17$ & $727 \pm 3$ & $69.04 \pm 1.50$ & $5.57 \pm 0.14$ \\
\hline 4 & $15 \mathrm{~h}$ in $\mathrm{N} 719 / 2 \mathrm{~h}$ in LP-2 & $1.09 \times 10^{-7} / 6.07 \times 10^{-8}$ & $13.23 \pm 0.33$ & $725 \pm 6$ & $67.97 \pm 2.00$ & $6.41 \pm 0.17$ \\
\hline 5 & $5 \mathrm{~h}$ in $\mathrm{LP}-2 / 21 \mathrm{~h}$ in N719 & $2.53 \times 10^{-8} / 1.16 \times 10^{-7}$ & $14.30 \pm 0.20$ & $765 \pm 5$ & $69.95 \pm 1.00$ & $7.72 \pm 0.11$ \\
\hline
\end{tabular}

${ }^{a}$ The dye loading amounts $(T)$ were obtained from the absorption spectra of the desorpting $\mathrm{NaOH}$ solution of the single- and co-sensitized TiO ${ }_{2}$ photoanode.

\subsection{DSSCs assembly and characterization}

In this work, 0.1 M DMPII, 0.5 M 4-TBP, 0.5 M LiI and 0.03 $\mathrm{M} \mathrm{I}_{2}$ dissolving in acetonitrile/valeronitrile (volume ratio of 85/15) were used as the electrolyte. The active area of the $\mathrm{TiO}_{2}$ film is $0.16 \mathrm{~cm}^{2}$. For the fabrication of DSSCs, the photoanode and counter electrode (Pt sheet) were assembled in sandwich-type cells with injection of the electrolyte. UV-visible absorption spectra of the dye in solution $\left(3 \times 10^{-6} \mathrm{M}\right.$ in ethanol) and adsorbed on $\mathrm{TiO}_{2}$ films ( $\left.3 \mu \mathrm{m}\right)$ was measured by a Shimadzu UV1800 spectrometer. To determine the dye loading amounts on $\mathrm{TiO}_{2}$ films, the photoanodes were immersed into $0.1 \mathrm{M}$ solution of $\mathrm{NaOH}$ in water/ethanol (volume ratio of 1/1), and then the absorption spectra of the desorbed dye solutions also measured by the Shimadzu UV-1800 spectrometer. The distributions of the $\mathrm{Zn}$ and $\mathrm{Ru}$ element in the two dye molecules along the $\mathrm{TiO}_{2}$ film depth were investigated by energy dispersive spectrometer (EDS, Hitachi S4800) and electron probe microanalysis (EPMA, JEOL JXA-8100). The photocurrent density-voltage $(J-V)$ characteristics of DSSCs were measured under illumination with a solar simulator (solar AAA simulator, AM 1.5 G, Oriel China) and the incident light was adjusted with a calibrated Si solar cell (National Institute of Metrology, China). All the photovoltaic parameters are the averaged results from three parallel devices, and the error is displayed in Table 1 . The IPCE was measured by using a commercial setup (QTest Station 2000 IPCE Measurement System, CROWNTECH, USA). A 300 W xenon lamp (Newport, USA) was used to give the incident light ranging from 300 to $800 \mathrm{~nm}$. All the IPCE values are the medium results from three parallel devices, and the error in IPCE values is within $\pm 2 \%$. EIS was carried out by employing an electrochemical analyzer (CHI660 Chenhua, China) under dark condition, and for open-circuit voltage decay (OCVD) from light ON to OFF.

\section{Results and discussion}

\subsection{Characteristics of LP-2 and N719}

The chemical structures of LP-2 and N719 are shown in Fig. 1. The carboxylic acid group in the dye LP-2 serves as the anchoring group which binds to the surface of $\mathrm{TiO}_{2}$, while the dye N719 contains four anchoring units which could bind to $\mathrm{TiO}_{2}$ via two neighboring carboxylic acid/carboxylate groups. ${ }^{50}$ Therefore, the different anchoring modes probably lead to the difference in the binding energies onto $\mathrm{TiO}_{2}$ films.

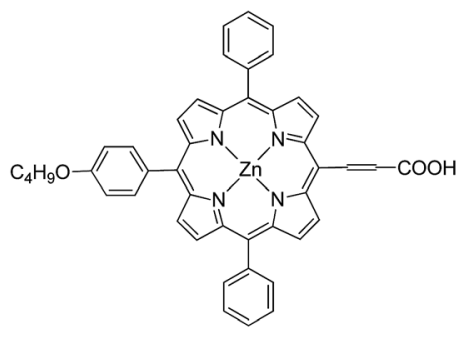

LP-2

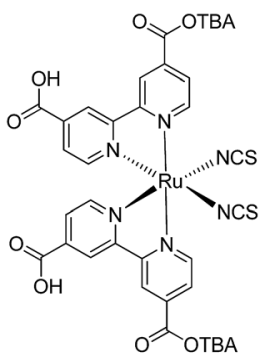

N719
Fig. 1 Molecular structures of LP-2 and N719
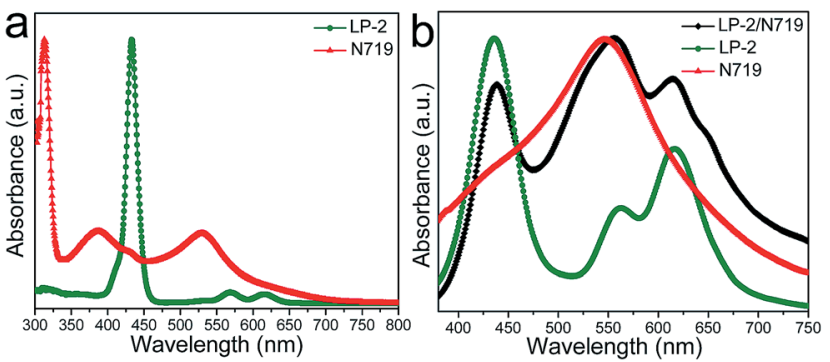

Fig. 2 Absorption spectra of LP-2 and N719 in ethanol solution (3.0 $\times$ $10^{-6}$ M) (a) and LP-2, N719, and LP-2 and N719 co-adsorbed on $\mathrm{TiO}_{2}$ films (thickness $3 \mu \mathrm{m}$ ) (b).

Fig. 2a shows the UV-vis absorption spectra of LP-2 and N719 in ethanol solution. LP-2 exhibits an intense Soret band in the range of 400-450 $\mathrm{nm}$ and two moderate $\mathrm{Q}$ bands in the 550$650 \mathrm{~nm}$ range. For N719, the light absorbance is far less in the 400-500 $\mathrm{nm}$ and $600-750 \mathrm{~nm}$ regions than that between $500-$ $600 \mathrm{~nm}$. The absorption spectrum of LP-2 well compensates that of N719, resulting in the panchromatic absorption of the co-sensitized solar cell from 300 to $750 \mathrm{~nm}$. The normalized absorption spectra of the individual dye on $\mathrm{TiO}_{2}$ films is presented in Fig. 2b. The absorption bands of the dyes on thin $\mathrm{TiO}_{2}$ films are significantly broadened compared to that in ethanol solution, which is ascribed to the interaction between the anchoring unit and the $\mathrm{TiO}_{2}$ surface. When LP-2 and N719 were co-sensitized on the $\mathrm{TiO}_{2}$ film, the spectrum covered the light absorption regions of the two dyes. Therefore, based on their absorption spectra of the $\mathrm{TiO}_{2}$ film, LP-2 and N719 maybe a promising couple for the co-sensitized solar cells. 


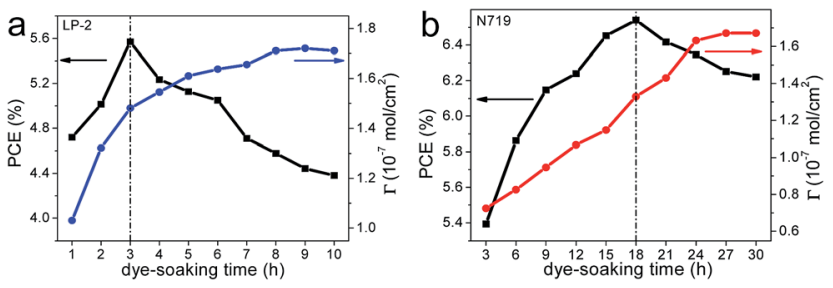

Fig. 3 The relation between the PCE, dye-loading amounts $(T)$ and dye-soaking hour for LP-2 (a) and N719 (b).

However, in addition to the mentioned prerequisites of the complementary absorption spectra for LP-2 and N719, the adsorption rate and loading amounts for each dye have great influence on the co-sensitized cell device performance. When the concentration of each dye solution is determined, the $\mathrm{TiO}_{2}$ films soaking hour tends to affect the dye-loading amount. The PCE of the cell devices based on the single sensitizer (LP-2 or N719) were then obtained, in which the $\mathrm{TiO}_{2}$ photoanodes were prepared under different dye-soaking hour, thus leading to different dyeloading amounts on $\mathrm{TiO}_{2}$ photoanodes. Hence, the relations between the PCE and the dye-loading amount as a function of the dye-soaking hour for LP-2 and N719 are shown in Fig. 3a and b. The dye-loading amount is calculated by fitting the absorption plots (Fig. S1†) of the desorbed dye solution from $\mathrm{TiO}_{2}$ films into Lambert-Beer law. In Fig. 3a and b, with the dye-soaking hour increasing from $1 \mathrm{~h}$ to $8 \mathrm{~h}$ and $1 \mathrm{~h}$ to $27 \mathrm{~h}$ for LP-2 and N719, respectively, the dye-loading amount keeps increasing. After $8 \mathrm{~h}$ and $27 \mathrm{~h}$ of the LP-2- and N719-soaking time, the dye-loading amount remains unchanged, which means that LP-2 and N719 reached the saturated loading on $\mathrm{TiO}_{2}$. From Fig. $3 \mathrm{a}$ and b, it also can be seen that the PCE of the cell devices sensitized with LP-2 and $\mathrm{N} 719$ achieve the maximum of $5.57 \%$ and $6.54 \%$ at $3 \mathrm{~h}$ and $18 \mathrm{~h}$ rather than $8 \mathrm{~h}$ and $27 \mathrm{~h}$, respectively. The results indicate that optimal dye-soaking hour and loading amount are necessary for the achievement of the best cell performance. It is believed that the extra dye-soaking hour and loading amounts will lead to serious dye aggregation on the $\mathrm{TiO}_{2}$ surface, resulting in the decreasing of the cell performance. Furthermore, it can be observed that the loading amount of LP-2 reaches $1.48 \times$ $10^{-7} \mathrm{~mol} \mathrm{~cm}^{-2}$ at $3 \mathrm{~h}$, but that of N719 reaches $1.33 \times 10^{-7} \mathrm{~mol}$ $\mathrm{cm}^{-2}$ at $18 \mathrm{~h}$, clearly indicating that the adsorption rate of LP-2 is much greater than that of $\mathrm{N} 719$ on $\mathrm{TiO}_{2}$ films, which will influence the loading amounts of the co-sensitizers.

\subsection{Co-sensitization of LP-2 and N719 in DSSCs}

In order to achieve panchromatic DSSCs for better performance, the co-sensitization technique was applied by using LP-2 and N719 with the complementary absorption spectra. In general, two approaches are developed for co-sensitization: the cocktail and stepwise procedure..$^{54}$ For the cocktail co-sensitization, the $\mathrm{TiO}_{2}$ film is soaked into a solution of the dye mixture of LP-2 and N719 at a certain molar ratio. In the stepwise procedure, two dye molecules in individual solutions sequentially adsorbs on the $\mathrm{TiO}_{2}$ film. The soaking sequence will influence the loading for each dye molecule, and thus the resultant cell performance.
Upon optimization, the performance of different devices was evaluated by measuring the photocurrent density-voltage $(J-V)$ curves (as shown in Fig. 4) and the photovoltaic parameters, as well as the dye-loading amounts for each dye molecule in the devices, summarized in Table 1 . The molar ratio between cosensitizers N719 and LP-2 was optimized for the cocktail-type DSSC, and the photovoltaic parameters are summarized in Table S1. $\dagger$ The device 3, in which the $\mathrm{TiO}_{2}$ film was soaked in a mixing solution with the molar ratio of N719 to LP-2 at $10: 1$ for $20 \mathrm{~h}$, shows the best performance. It is found that the efficiency $(6.93 \%)$ of the device 3 is a just bit greater than that of the single N719-sensitized solar cell (device 1) or LP-2-based cell (device 2). On the other hand, the loading amounts of LP-2 (6.68 $\left.\times 10^{-8} \mathrm{~mol} \mathrm{~cm}^{-2}\right)$ are very close to those of N719 $(7.35 \times$ $10^{-8} \mathrm{~mol} \mathrm{~cm}^{-2}$ ) in device 3 , which suggests that the loading amounts of LP-2 are similar to that of N719. Since the device 1 yields the greater cell device efficiency than 2 (as shown in Table 1), the co-sensitization is aimed at enhancing the cell device performance by introducing LP-2 as a co-sensitizer and N719 as the primary sensitizer adsorbed on the $\mathrm{TiO}_{2}$ film. However, based on above results, the loading amounts of N719 in device 3 only take up $55.3 \%$ of that $\left(1.33 \times 10^{-7} \mathrm{~mol} \mathrm{~cm}^{-2}\right)$ in device 1 , which gives rise to the relatively low cell performance improvement of device 3 with regard to that of device 1 . Interestingly, the open-circuit voltage $\left(V_{\mathrm{oc}}\right)$ of device 3 is much lower than that of 1 , which is probably due to the long loading time of LP-2 resulting in serious dye aggregation on the $\mathrm{TiO}_{2}$ film, and subsequent low $V_{\mathrm{oc}}$. The results are ascribed to the different adsorption rates of LP-2 and N719, i.e., the much greater adsorption rate of LP-2 makes the unbalance of the loading amounts for two molecules on $\mathrm{TiO}_{2}$ films.

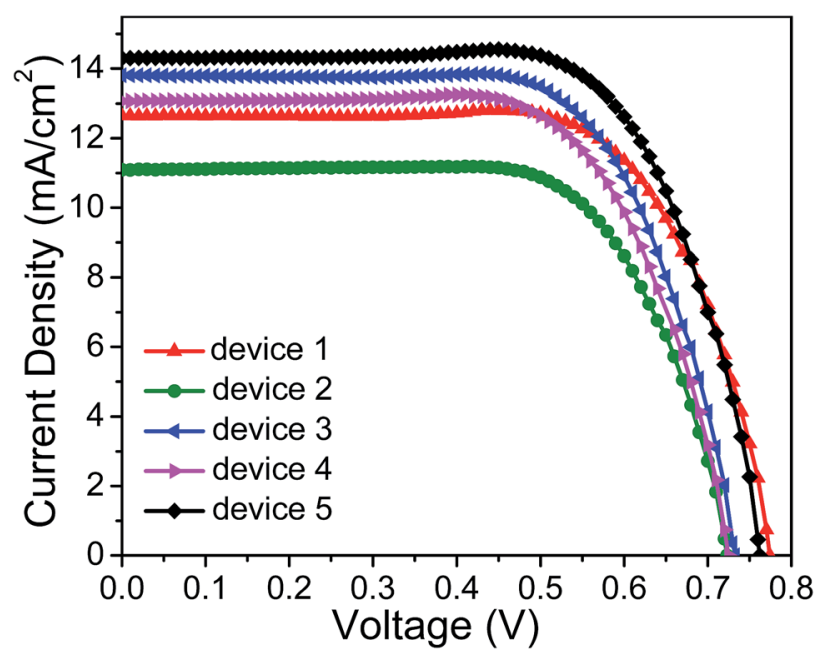

Fig. 4 The J-V curves of cell devices fabricated with LP-2, N719 and LP-2/N719 sensitized $\mathrm{TiO}_{2}$ electrodes under simulated AM $1.5 \mathrm{G}$ irradiation; $\mathrm{TiO}_{2}$ photoanode thickness $20 \mu \mathrm{m}$, active area $0.16 \mathrm{~cm}^{2}$ (device 1 fabricated with $\mathrm{TiO}_{2}$ electrode soaked in N719 solution for 18 h; device 2 in LP-2 solution for 3 h; device 3 in LP-2/N719 (1/10) solution for $20 \mathrm{~h}$; device 4 in N719 for $15 \mathrm{~h}$ and in LP-2 for $2 \mathrm{~h}$ sequentially; and device 5 in LP-2 for $5 \mathrm{~h}$ and in N719 for $21 \mathrm{~h}$ sequentially). 
To further investigate the influence of the adsorption rates and loading amounts of LP-2 and N719 on the cell performance and further improve the performance of the co-sensitized solar cell, the devices 4 and 5 were fabricated by immersing the $\mathrm{TiO}_{2}$ films in the solutions of a single dye LP-2 and N719 in sequence. The soaking hour in single dye solutions was optimized for the stepwise-type DSSCs. The device 4 with $\mathrm{TiO}_{2}$ films first immersed in the solution of N719 for $15 \mathrm{~h}$ and then in LP-2 solution for $2 \mathrm{~h}$ achieved the best performance, and for device 5 , in LP-2 solution for $5 \mathrm{~h}$ and in N719 solution for $21 \mathrm{~h}$. From Table 1, the loading amounts of N719 in device 4 reach $1.09 \times$ $10^{-7} \mathrm{~mol} \mathrm{~cm}{ }^{-2}$, which is close to that in device 1 , and the loading amounts of LP- 2 in device 4 account for $41.1 \%$ relative to that in device 2. Moreover, the total loading amounts of two dye molecules on the $\mathrm{TiO}_{2}$ films is $1.70 \times 10^{-7} \mathrm{~mol} \mathrm{~cm}^{-2}$, which far surpasses that in device 1 and 2 and further leads to the serious aggregation on $\mathrm{TiO}_{2}$ films. As shown, the device 4 exhibits the lower PCE of $6.41 \%$ than that (6.54\%) of device 1 . The short-circuit photocurrent $\left(J_{\mathrm{sc}}\right)$ shows a slight enhancement from 12.65 to $13.03 \mathrm{~mA} \mathrm{~cm}^{-2}$, but the $V_{\mathrm{oc}}$ significantly decreases from 779 to $725 \mathrm{mV}$. Therefore, it is similar to that observed for device 3 that the introduction of the second dye molecule (LP-2) onto the $\mathrm{TiO}_{2}$ surface in device 4 probably increases the lightharvesting, resulting in the enhanced $J_{\mathrm{sc}}$ compared to that in device 1. However, the aggregation of LP-2 simultaneously decreases the $V_{\text {oc }}$ for device 4 . The combined effects of LP-2 on the $J_{\mathrm{sc}}$ and $V_{\mathrm{oc}}$, as well as the excess loading amounts of dye molecules in device 4 , leads to relatively poorer performance of device 4 than that of device 1 . Furthermore, it is shown that when the loading time of LP-2 on the $\mathrm{TiO}_{2}$ film decreases, the devices can not give any better results (Table $\mathrm{S} 2 \dagger$ ). Although the $V_{\text {oc }}$ is slightly increased from $725 \mathrm{mV}$ to $738 \mathrm{mV}$ by adjusting the loading time of LP-2, the $J_{\mathrm{sc}}$ is reduced to $12.57 \mathrm{~mA} \mathrm{~cm}^{-2}$, and ultimately, the even lower efficiency is obtained. The results further demonstrate the influence of the secondly introduced LP-2 on the cell performance, and indicate that N719 firstly adsorbed on the $\mathrm{TiO}_{2}$ film may inhibit the effective permeation of LP-2 along the $\mathrm{TiO}_{2}$ film depth. ${ }^{41}$ Therefore, for device 4, LP-2 with low mobility is difficult to adsorb on the unoccupied positions of $\mathrm{TiO}_{2}$ films along the $\mathrm{TiO}_{2}$ film depth, and the aggregation of LP-2 is formed.

Intriguingly, the device 5 , in which the sensitized photoanode was prepared in a reverse dye-loading order (in LP-2 solution for $5 \mathrm{~h}$ and then in N719 for $21 \mathrm{~h}$ ) exhibited the significantly enhanced cell performance among all the single- and cosensitized solar cells, which yielded a promising PCE of $7.72 \%$ (with a $J_{\mathrm{sc}}$ of $14.30 \mathrm{~mA} \mathrm{~cm}^{-2}$, a $V_{\mathrm{oc}}$ of $765 \mathrm{mV}$ and a $\mathrm{FF}$ of $69.95 \%$ ) relative to $6.54 \%$ and $5.57 \%$ for devices 1 and 2, respectively. Furthermore, the loading amount of LP-2 in device 5 is $2.53 \times$ $10^{-8} \mathrm{~mol} \mathrm{~cm}^{-2}$ which is much lower than $1.61 \times 10^{-7} \mathrm{~mol} \mathrm{~cm}^{-2}$ (in Fig. 3a) representing the loading amount of LP-2 when the device was sensitized with the single LP-2 for $5 \mathrm{~h}$. However, the total loading amount of two dyes is $1.41 \times 10^{-7} \mathrm{~mol} \mathrm{~cm}{ }^{-2}$, which is close to that of N719 and LP-2 in devices 1 and 2, respectively. Therefore, it is believed that the competitive adsorption exists in the process of the post-adsorption of N719, i.e., some of the preadsorbed LP-2 molecules are replaced by N719. By competitive adsorption loading, the extra LP-2 is replaced by N719, which seems to have stronger binding to the $\mathrm{TiO}_{2}$ surface. Thus, in device 5 , the aggregation is efficiently suppressed and thus, the $V_{\text {oc }}$ value of device 5 is found to be close to that of device 1 . Simultaneously, due to the complementary light absorbance of two dye molecules in the sunlight spectrum, the light-harvesting increases, leading to the significantly improved $J_{\mathrm{sc}}$ value for device 5 compared to those of other single dye- or co-sensitized solar cells.

\subsection{Insight into the competitive adsorption between LP-2 and N719 on $\mathrm{TiO}_{2}$ films}

The loading amounts of LP-2 on the co-sensitized $\mathrm{TiO}_{2}$ film in device 5 are found to be $2.53 \times 10^{-8} \mathrm{~mol} \mathrm{~cm}^{-2}$, as shown in Table 1 . This value is significantly lower than $1.61 \times 10^{-7} \mathrm{~mol}$ $\mathrm{cm}^{-2}$, ascribed to the loading amounts of LP-2 desorbed from the single LP-2-sensitized $\mathrm{TiO}_{2}$ film after dipping into the LP-2 solution for $5 \mathrm{~h}$. In order to further understand the difference in the LP-2 loading amounts between the single LP-2-sensitized $\mathrm{TiO}_{2}$ films and the co-sensitized ones, a series of photoanodes sensitized by the single LP-2 and co-sensitized first by LP-2 and then by N719 were prepared. The loading time for LP- 2 varied from $2 \mathrm{~h}, 5 \mathrm{~h}$ to $8 \mathrm{~h}$ and the photoanodes were then denoted as PL2, PL5 and PL8, respectively, and for N719 it was fixed for $21 \mathrm{~h}$ (denoted as PL2 +21 , PL5 +21 and PL8 +21 ). The UV-vis absorption spectra of the desorbed LP-2 solution for PL2, PL5, PL8, PL2 + 21, PL5 + 21 and PL8 + 21 are all shown in Fig. 5a. It can be observed that with the increasing of the LP-2-loading time from 2 to $8 \mathrm{~h}$, the loading amounts of LP- 2 without the post-adsorption of N719 increases from 1.32 to $1.71 \times 10^{-7} \mathrm{~mol}$ $\mathrm{cm}^{-2}$ and those with the post-adsorption of N719 also shows the trend of increasing. However, the loading amounts of LP-2 for the co-sensitized photoanodes (PL2 + 21, PL5 + 21 and PL8 + 21) significantly drop compared to those for the single LP-2sensitized ones (PL2, PL5 and PL8). Obviously, the dramatic reduction of the loading amounts of LP-2 could be induced by the co-sensitization of N719. Furthermore, a series of photoanodes co-sensitized first by LP-2 and then by N719, the loading time for N719 varied from $10 \mathrm{~h}, 21 \mathrm{~h}$ to $28 \mathrm{~h}$ and for LP-2 it was fixed for $5 \mathrm{~h}$ (denoted as PN5 + 10, PN5 +21 and PN5 + 28), were also obtained. It is found that with the increasing of the N719 loading time, the loading amounts of LP-2 decrease based on the UV-vis absorption spectra of the desorbed LP-2 solution for PN5 +10 , PN5 +21 and PN5 +28 as shown in Fig. 5b. The results further suggests that the loading amounts of LP-2 are remarkably influenced by N719. In order to determine the desorption amounts of LP-2 influenced by the competitive adsorption of N719 in device 5, Fig. S2a $\dagger$ shows the absorption spectra of the desorbed LP-2 solution for PL5 and PL5 + 21, and the solventeffect-desorbed LP-2 solution which was obtained by soaking the PL5 into the ethanol solvent for $21 \mathrm{~h}$ representing the loading time of N719 in device 5 (denoted as PL5 + SE21). It is calculated by Lambert-Beer law that the desorption amounts of LP-2 for PL5, PL5 + 21 and PL5 + SE21 are $1.61 \times 10^{-7}, 2.5 \times$ $10^{-8}$ and $4.8 \times 10^{-8} \mathrm{~mol} \mathrm{~cm}{ }^{-2}$, respectively, as is shown in Fig. S2b. $\dagger$ As a result, it is found that the desorption amounts of 

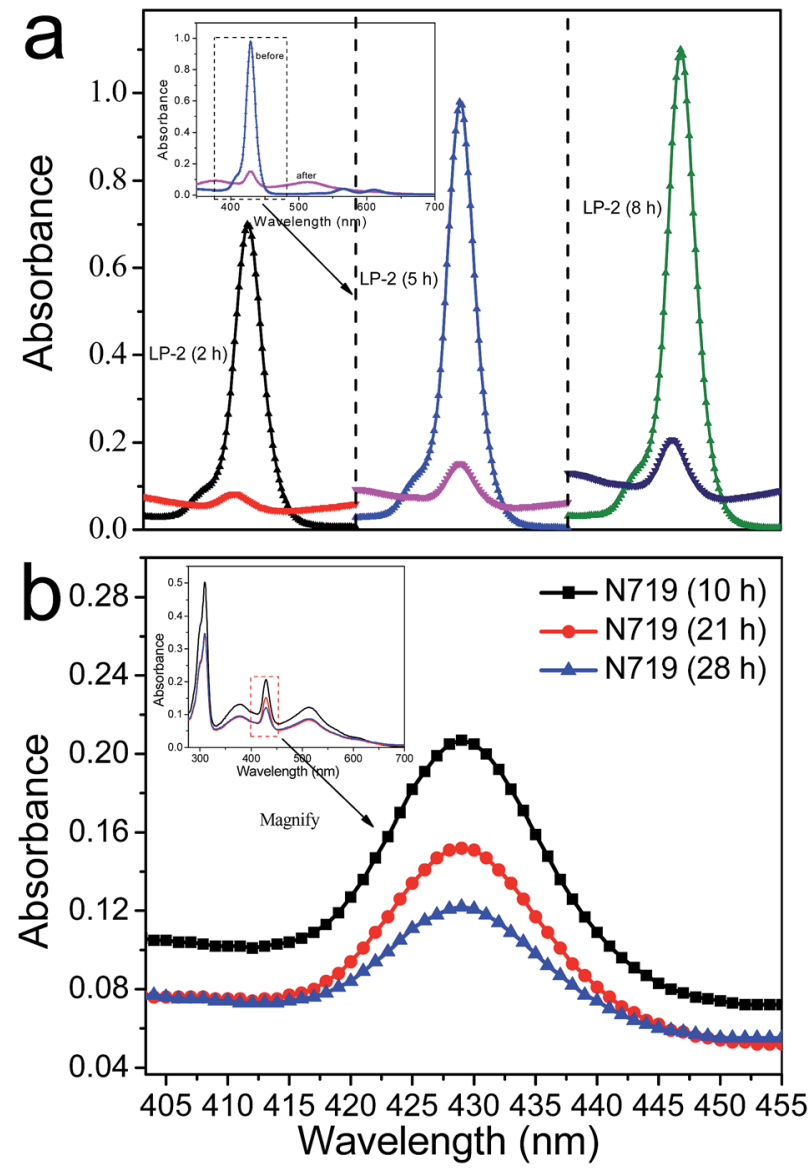

Fig. 5 UV-vis absorption spectra of the desorbed solutions for PL2, PL5, PL8, PL2 + 21, PL5 + 21 and PL8 + 21 (a), and for PN5 + 10, PN5 + 21 and PN5 +28 (b). (Inset showing the full absorption plots of the desorbed solutions. PL and PN representing the photoanodes sensitized with dyes. PL2, PL5 and PL8 showing the $\mathrm{TiO}_{2}$ electrode sensitized with LP-2 for 2, 5 and 8 h respectively; PL2 $+21, P L 5+21$ and PL8 +21 showing the photoanodes sensitized with LP- 2 for some time and then with $\mathrm{N} 719$ for $21 \mathrm{~h}$; PN5 + 10, PN5 + 21 and PN5 + 28 showing the photoanodes sensitized with LP-2 for $5 \mathrm{~h}$ and then with LP-2 for some time.)

LP-2 influenced by the competitive adsorption of N719 (PL5 + $\mathrm{N} 21$ ) reach $8.8 \times 10^{-8} \mathrm{~mol} \mathrm{~cm} \mathrm{~cm}^{-2}$ calculated by deducting those for PL5 + 21 and PL5 + SE21 from that for PL5. Therefore, it is believed that $54.7 \%$ of the loading amount of the pre-adsorbed LP-2 dye is replaced by the post-adsorption of the N719 dye, leading to the balance of the loading amounts for two dye molecules on $\mathrm{TiO}_{2}$ films.

Furthermore, in order to explore the distribution of the LP-2 and N719 dye molecules across the $\mathrm{TiO}_{2}$ film influenced by the competitive adsorption in device 5, EDS was used to characterize the elemental distribution maps (the relative zinc ( $\mathrm{Zn}$ ) and ruthenium $(\mathrm{Ru})$ content representing the amount of the LP2 and N719 dye molecules, respectively), and EPMA used to investigate the relative amounts of different elements along the $\mathrm{TiO}_{2}$ film depth, ${ }^{\mathbf{4 1 , 5 5}}$ as displayed in Fig. 6. Fig. 6a shows the SEM image of the cross section across the $\mathrm{TiO}_{2}$ film from the surface to the FTO glass, and the elemental mapping images of Ru and
$\mathrm{Zn}$ are shown in Fig. $6 \mathrm{~b}$ and c, respectively. It is observed that $\mathrm{Ru}$ and $\mathrm{Zn}$ are distributed along the whole cross section, which suggests the efficient penetration of N719 into the inner of the $\mathrm{TiO}_{2}$ film by the competitive adsorption. Moreover, the cosensitized photoanode PL5 +21 was subjected to EPMA to further measure the distribution of the actual contents of $\mathrm{Zn}$ and $\mathrm{Ru}$ (as displayed in Fig. S3†) denoted as CZX and CRX ( $X$ representing the $\mathrm{TiO}_{2}$ film depth), respectively. Fig. 6d shows the distributions of the relative amounts between LP-2 and N719 along the $\mathrm{TiO}_{2}$ film, which are achieved by $\mathrm{CZX} /(\mathrm{CZX}+$ $\mathrm{CRX})$ and $\mathrm{CRX} /(\mathrm{CZX}+\mathrm{CR} X)$, respectively. Actually, after the $\mathrm{TiO}_{2}$ film is first sensitized with LP-2 for $5 \mathrm{~h}$, the positions of the $\mathrm{TiO}_{2}$ film are occupied only by the LP- 2 dye molecules, and the relative amounts of LP- 2 is regarded as $100 \%$. However, when co-sensitized with $\mathrm{N} 719$ for $21 \mathrm{~h}$, the $\mathrm{TiO}_{2}$ film is greatly covered by N719. The relative amounts of LP-2 are significantly lower than that of $\mathrm{N} 719$ over the $\mathrm{TiO}_{2}$ film, i.e., most of the positions of the $\mathrm{TiO}_{2}$ surface are occupied by N719. The relative amounts of N719 reach $67 \%$ at $\sim 16 \mu \mathrm{m}$, which means that most of LP-2 are replaced by $\mathrm{N719}$, and on the other hand, the $\mathrm{TiO}_{2}$ film is covered by both N719 and LP-2 along the $\mathrm{TiO}_{2}$ film depth.

Thereby, it is supposed that the aggregation of the LP-2 dye molecule is reduced by the competitive adsorption of the N719 dye molecule. On the basis of the above results, it can be explained from the adsorption modes (Fig. S4 $\dagger$ ) that the N719 dye molecule possessing four anchoring units including two carboxylic acid groups and two carboxylate can strengthen their binding onto the $\mathrm{TiO}_{2}$ surface comparing to the LP-2 dye molecule including one carboxylic acid group. ${ }^{50}$ However, when the $\mathrm{TiO}_{2}$ film is sensitized with N719 and LP-2 sequentially, N719 is not replaced by LP-2 from the view point of the change of the loading amount of N719 (Table S3 $\uparrow$ ). And we draw a conclusion that the competitive adsorption of N719 versus LP-2 is efficient, whereas there is not the competitive adsorption in the reverse adsorption sequence. Therefore, the results of the detailed investigation including the change of the loading amounts, the distribution and the relative amounts of the two dye molecules along the $\mathrm{TiO}_{2}$ film depth reveal that there is the competitive adsorption in the process of LP-2 and N719 adsorbed on $\mathrm{TiO}_{2}$ films in sequence, and $54.7 \%$ of the pre-adsorbed LP-2 is replaced by the post-adsorption of N719, which contribute to the significantly improved performance of device 5 .

\subsection{Photovoltaic performance and electrochemical behaviors analysis of DSSCs with stepwise co-sensitization}

The incident photo-to-current conversion efficiency (IPCE) spectra of the DSSCs sensitized with the individual dyes, N719 and LP-2 (devices 1 and 2, respectively) and the co-sensitizers stepwisely adsorbed on $\mathrm{TiO}_{2}$ films (device 5) were measured and presented in Fig. 7a. It is found that the device 2 shows high IPCE in the range 400-500 $\mathrm{nm}$ and 550-650 $\mathrm{nm}$ corresponding to the Soret-band and Q-band absorption in the UV-vis absorption spectra respectively, reaching the maximum value of $68 \%$ at $436 \mathrm{~nm}$, while the IPCE spectra of the device 1 covers a broad wavelength from 350-700 $\mathrm{nm}$ but displaying the relatively lower IPCE value (maximum value $58 \%$ at $523 \mathrm{~nm}$ ). After 

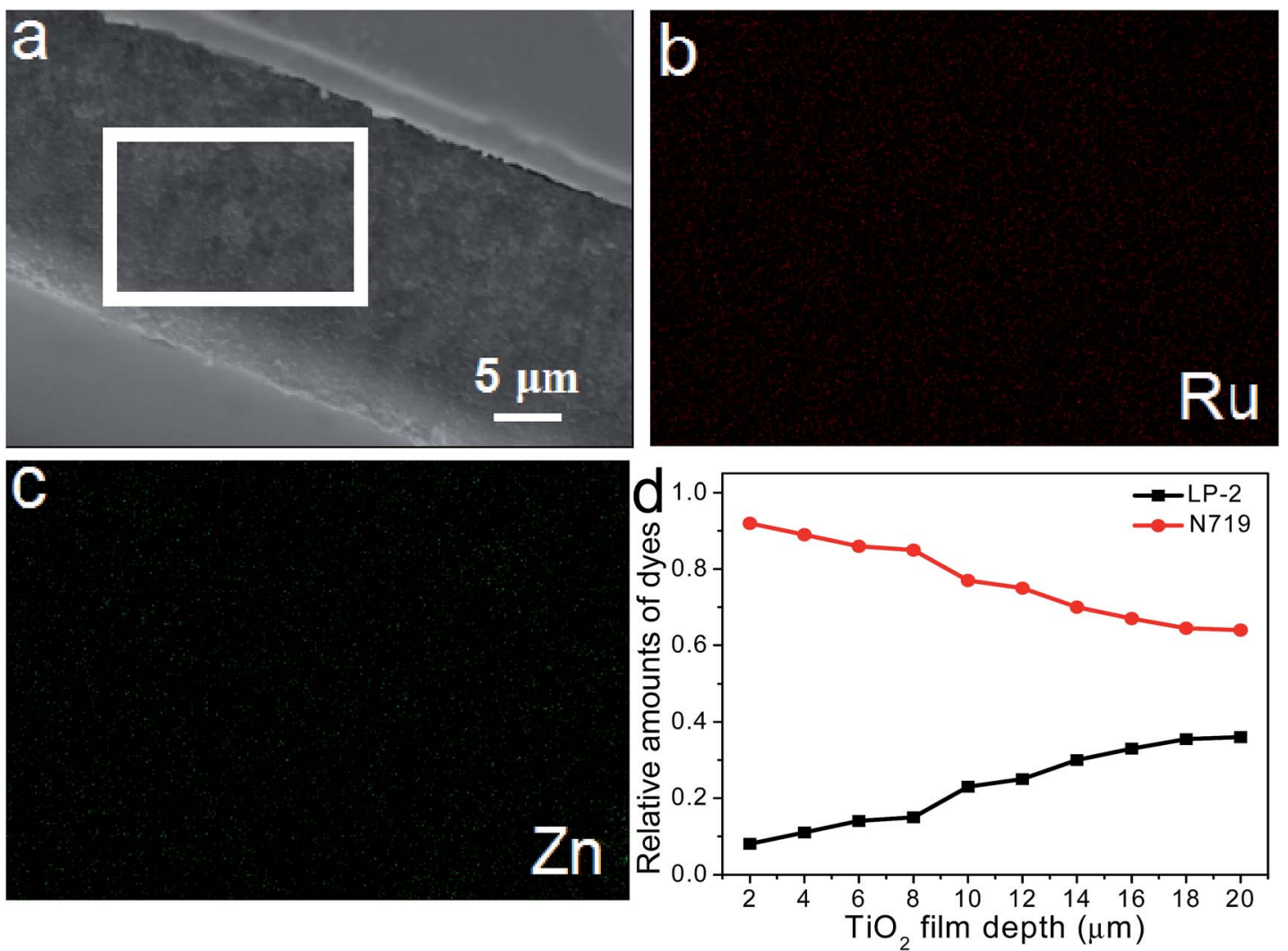

Fig. 6 (a) SEM image of the cross section along the $\mathrm{TiO}_{2}$ film in device $5\left(\mathrm{TiO}_{2}\right.$ electrode first sensitized with $\mathrm{LP}-2$ for $5 \mathrm{~h}$ and then with $\mathrm{N} 719$ for $21 \mathrm{~h}$ ), (b) and (c) the elemental distribution maps of Ru and Zn, respectively, (Zn and Ru respectively representing LP-2 and N719), and (d) EPMA results showing the distribution of the relative amounts of LP-2 and N719 along the $\mathrm{TiO}_{2}$ film.
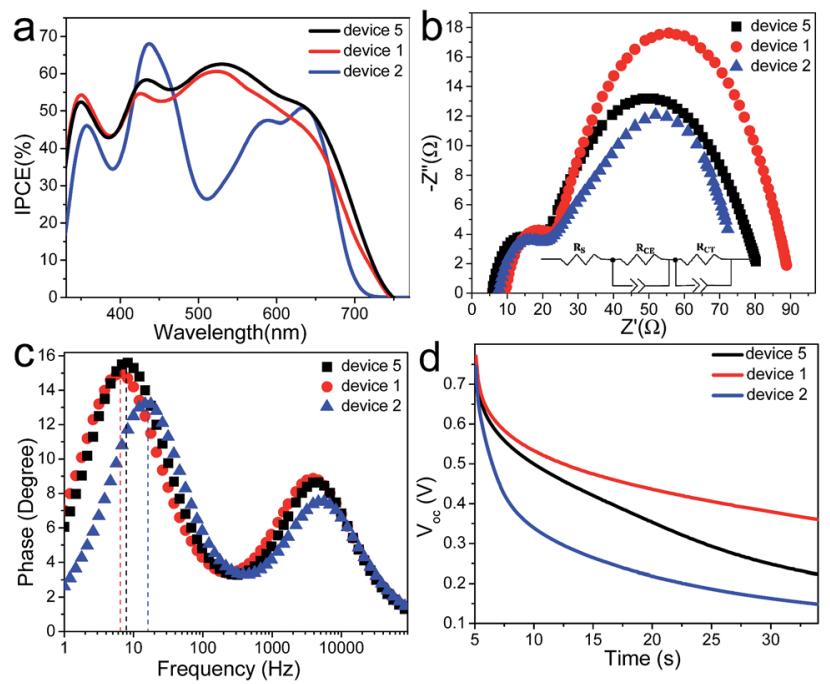

Fig. 7 The IPCE spectra (a), Nyquist plots (b), Bode plots (c) and OCVD profiles (d) for the devices 1,2 and 5 (device 1 fabricated with $\mathrm{TiO}_{2}$ electrode soaked in N719 solution for $18 \mathrm{~h}$, device 2 in LP-2 for $3 \mathrm{~h}$, and device 5 in LP-2 for $5 \mathrm{~h}$ and N719 for $21 \mathrm{~h}$ sequentially showing the best performance).

sensitized with LP-2 and N719 sequentially, the device 5 exhibits the higher IPCE value than the device 1 in the range 420$700 \mathrm{~nm}$. All the IPCE values are the medium results from three parallel devices, and the error in IPCE values is within $\pm 2 \%$. The improvement of the IPCE value is attributed to the coadsorption of LP-2, which is also consistent with the UV-vis absorption spectra where the co-sensitized $\mathrm{TiO}_{2}$ films shows the increased light absorption (Fig. 2b). Therefore, the improved $J_{\mathrm{sc}}$ value in device $5\left(14.30 \mathrm{~mA} \mathrm{~cm}^{-2}\right)$, relative to 12.65 $\mathrm{mA} \mathrm{cm}{ }^{-2}$ and $11.09 \mathrm{~mA} \mathrm{~cm}^{-2}$ in device 1 and 2 respectively, is in good agreement with the improvement of the IPCE value. On the other hand, the better performance of the device 5 is also ascribed to the balance of the loading amounts of LP-2 and N719 by the competitive adsorption. Thus, a small number of the loading amount of LP-2 with high absorption coefficients (Table $\mathrm{S} 4 \dagger$ ) yields a sufficient optical density, thereby providing a sufficient space for the N719 dye yielding a complementary absorption spectra.

Electrochemical impedance spectroscopy (EIS) were employed to elucidate the interfacial charge recombination process in the device 1,2 and 5 at a forward bias of $-0.6 \mathrm{~V}$ with the frequency range of 1 to $10^{5} \mathrm{~Hz}$ under dark condition. Fig. $7 \mathrm{~b}$ and $\mathrm{c}$ show the Nyquist and Bode plots of their EIS spectra, respectively. The equivalent circuit is displayed in Fig. $7 \mathrm{~b}$ (inset). $R_{\mathrm{CT}}, R_{\mathrm{CE}}$ and $R_{\mathrm{S}}$ respectively represent the chargetransfer resistance at the $\mathrm{TiO}_{2} /$ dye/electrolyte interface and at the counter electrode, and the series resistance. The smaller semicircle in the Nyquist plots corresponds to $R_{\mathrm{CE}}$ and $R_{\mathrm{S}}$, and the larger semicircle corresponds to the $R_{\mathrm{CT}}$. In general, the $V_{\mathrm{oc}}$ 
is closely associated with the charge transfer at the $\mathrm{TiO}_{2} /$ dye/ electrolyte interface, i.e., the back reaction of the electrons in the $\mathrm{TiO}_{2}$ film with $\mathrm{I}_{3}{ }^{-}$species in the electrolyte.

The larger $R_{\mathrm{CT}}$ value indicates it is more difficult to transfer the injected electrons from the $\mathrm{TiO}_{2}$ back to the electrolyte, and thus the back recombination can be suppressed in the cell device, thus giving a higher $V_{\mathrm{oc}}$. It is found that the device 1 presents the largest $R_{\mathrm{CT}}\left(64 \Omega \mathrm{cm}^{-2}\right.$, Table $\left.\mathrm{S} 5 \dagger\right)$, and accordingly, the highest $V_{\mathrm{oc}}(779 \mathrm{mV})$ is achieved for the device 1 among all the three devices. The $V_{\text {oc }}$ values of the other two devices (2 and 5) are found to be $727 \mathrm{mV}$ and $765 \mathrm{mV}$, corresponding to $R_{\mathrm{CT}}$ values of $48 \Omega \mathrm{cm}^{-2}$ and $58 \Omega \mathrm{cm}^{-2}$, respectively. Obviously, the trend of the $R_{\mathrm{CT}}$ observed here is consistent with that of the $V_{\text {oc }}$ value. However, for the cosensitized device 5 , the $V_{\mathrm{oc}}$ slightly decreases compared to that of the device 1. The introduction of LP-2 with the lower $V_{\text {oc }}$ as the co-sensitizer probably results in the lowering of the $\mathrm{TiO}_{2}$ Fermi level, and thus decreases the $V_{\text {oc }}$ of the device $5 .^{31}$ As a result, the $V_{\mathrm{oc}}$ value of the device 5 falls in between those of the devices 1 and 2 .

The electron lifetimes $\left(\tau_{\mathrm{e}}\right)$ in the devices 1,2 and 5 were calculated from the Bode plots as shown in Fig. 7c, using $\tau_{\mathrm{e}}=1$ / $(2 \pi f)$, where $f$ is the frequency at the maximum of the plot at the lower frequency region, which is related to the charge recombination rate. The longer $\tau_{\mathrm{e}}$ is indicative of the less electron recombination rate, thus leading to the improvement of the $V_{\mathrm{oc}}$ value. ${ }^{56}$ The obtained $\tau_{\mathrm{e}}$ values of the three devices are listed in Table S5. $\dagger$ It is found that the electron lifetime of the device 1, 2 and 5 is $25.16,9.91$ and $20.65 \mathrm{~ms}$, respectively. In other words, the device 1 and 2 display the longest and shortest electron lifetime and the $\tau_{\mathrm{e}}$ value of the device 5 falls in between them, which corresponds to the trend of the $V_{\text {oc }}$ value of the three devices.

Kinetics measurement of open-circuit voltage decay (OCVD) in DSSCs can reveal the characteristics of the electron lifetime and the electron recombination. ${ }^{57}$ The OCVD technique consists of turning off the illumination in a steady state and monitoring the subsequent decay of the $V_{\text {oc }}$. Fig. $7 \mathrm{~d}$ shows the OCVD curves of the devices 1, 2 and 5. The correlation between the $V_{\mathrm{oc}}$ decay and $\tau_{\mathrm{e}}$ can be expressed by the following equation:

$$
\tau_{\mathrm{e}}=-\frac{K_{\mathrm{B}} T}{e}\left(\frac{\mathrm{d} V_{\mathrm{oc}}}{\mathrm{d} t}\right)^{-1}
$$

where $e$ is the electron charge, $K_{\mathrm{B}}$ is Boltzmann constant, and $T$ is temperature. Therefore, the electron lifetime can be extracted from the slope of the $V_{\text {oc }}$ decay curves, and the steeper slope indicates the shorter electron lifetime. As shown in Fig. 7d, the device 1 presents the smallest slope, suggesting the longest electron lifetime, and which is followed by the device 5 and 2 in sequence. The results are well consistent with the $V_{\text {oc }}$ and EIS analysis of the devices 1,2 and 5 .

\section{Conclusions}

In this work, we have presented that the stepwise cosensitization of $\mathrm{TiO}_{2}$ films with two metal-based sensitizers, i.e., a porphyrin dye (LP-2) and a ruthenium dye (N719), is an effective approach which can significantly improve the photovoltaic performance of DSSCs. The co-sensitized cell device 5 exhibits a PCE value of $7.72 \%$, which is improved by $18.0 \%$ and $38.6 \%$ with respect to the single LP-2 and N719-sensitized devices, respectively. The improved performance of the cosensitized cell device is attributed to the enhancement of the $J_{\text {sc }}$, which is mainly due to the complementary absorption spectra and the balanced loading amounts of LP- 2 and N719 by the competitive adsorption. It indicates that $54.7 \%$ of the preadsorbed LP-2 is replaced by the post-adsorption of N719 which can penetrate into the inner side of the $\mathrm{TiO}_{2}$ film probably due to the different binding energies between the two dye molecules. On the other hand, the $V_{\text {oc }}$ of the device 5 is a little bit lower than the highest $V_{\text {oc }}$ of the N719-sensitized cell, which is well agreement with the change of the electron lifetimes, as was demonstrated by the EIS and OCVD. The present work thus can provide a guidance to properly introduce of the cosensitizers onto the $\mathrm{TiO}_{2}$ films for the performance enhancement of the co-sensitized solar cells. Further studies on the loading procedure for the incorporation of a third small dye molecule for the co-sensitized DSSCs are in progress.

\section{Acknowledgements}

This work is supported by National Natural Science Foundation of China (No. 21476162), and China International Science and Technology Project (No. 2012DFG41980, 2016YFE0114900).

\section{References}

1 L. M. Goncalves, V. D. Z. Bermudez, H. A. Ribeiro and A. M. Mendes, Energy Environ. Sci., 2008, 1, 655-657.

2 M. Grätzel, Acc. Chem. Res., 2009, 42, 1788-1798.

3 M. Wu and M. Ma, J. Phys. Chem. C, 2014, 118, 16727-16742. 4 J. Dehaudt, J. Husson, L. Guyard, F. Oswald and D. Martineau, Renewable Energy, 2014, 66, 588-595.

5 M. K. Nazeeruddin, F. D. Angelis, S. Fantacci, A. Selloni, G. Viscardi, P. Liska, S. Ito, B. Takeru and M. Grätzel, J. Am. Chem. Soc., 2005, 127, 16835-16847.

6 C.-C. Chou, K.-L. Wu, Y. Chi, W.-P. Hu, S.-J. Yu, G.-H. Lee, C.-L. Lin and P.-T. Chou, Angew. Chem., Int. Ed., 2011, 50, 2054-2058.

7 T. Bessho, S. M. Zakeeruddin, C. Y. Yeh, E. W.-G. Diau and M. Grätzel, Angew. Chem., Int. Ed., 2010, 122, 6796-6799.

8 N.-N. Zhang, B. Zhang, J.-J. Yan, X.-D. Xue, X. Peng, Y.-C. Li, Y.-B. Yang, C.-G. Ju, C.-C. Fan and Y.-Q. Feng, Renewable Energy, 2015, 77, 579-585.

9 Y.-Q. Wang, B. Chen, W.-J. Wu, X. Li, W.-H. Zhu, H. Tian and Y.-S. Xie, Angew. Chem., Int. Ed., 2014, 53, 10779-10783.

10 M. Urbani, M. Grätzel, M. K. Nazeeruddin and T. Torres, Chem. Rev., 2014, 114, 12330-12396.

11 C. Magistris, S. Martiniani, N. Barbero, J. Park, C. Benzi, A. Anderson, C.-H. Law, C. Barolo and B. O'Regan, Renewable Energy, 2013, 60, 672-678.

12 T. Edvinsson, C. Li, N. Pschirer, J. Schöneboom, F. Eickemeyer, R. Sens, G. Boschloo, A. Herrmann, 
K. Müllen and A. Hagfeldt, J. Phys. Chem. C, 2007, 111, 15137-15140.

13 D. P. Hagberg, J. H. Yum, H. J. Lee, F. D. Angelis, T. Marinado, K. M. Karlsson, R. Humphry-Baker, L.-C. Sun, A. Hagfeldt, M. Grätzel and M. K. Nazeeruddin, J. Am. Chem. Soc., 2008, 130, 6259-6266.

14 J. Tang, J.-L. Hua, W.-J. Wu, J. Li, Z.-G. Jin, Y.-T. Long and H. Tian, Energy Environ. Sci., 2010, 3, 1736-1745.

15 S.-Y. Qu and H. Tian, Chem. Commun., 2012, 48, 3039-3051.

16 J. Zhang, F.-T. Lu, S.-B. Qi, Y.-M. Zhao, K.-P. Wang, B. Zhang and Y.-Q. Feng, Dyes Pigm., 2016, 128, 296-303.

17 S. Mathew, A. Yella, P. Gao, R. Humphry-Baker, B. F. E. Curchod, N. A. Astani, I. Tavernelli, U. Rothlisberger, M. K. Nazeeruddin and M. Grätzel, Nat. Chem., 2014, 6, 242-247.

18 B. O'Regan and M. Grätzel, Nature, 1991, 353, 737-740.

19 A. Abbotto, F. Sauvage, C. Barolo, F. D. Angelis, S. Fantacci, M. Grätzel, N. Manfredi, C. Marinzi and M. K. Nazeeruddin, Dalton Trans., 2011, 40, 234-242.

20 M. Akhtaruzzaman, A. Islam, F. Yang, N. Asao, E. Kwon, S. P. Singh, L.-Y. Han and Y. Yamamoto, Chem. Commun., 2011, 47, 12400-12402.

21 A. Hagfeldt, G. Boschloo, L.-C. Sun, L. Kloo and H. Pettersson, Chem. Rev., 2010, 110, 6595-6663.

22 Y. Liu, H. Lin, J. T. Dy, K. Tamaki, J. Nakazaki, D. Nakayama, S. Uchida, T. Kubo and H. Segawa, Chem. Commun., 2011, 47, 4010-4012.

23 G. D. Sharma, G. E. Zervaki, P. A. Angaridis, A. Vatikioti, K. S. V. Gupta, T. Gayathri, P. Nagarjuna, S. P. Singh, M. Chandrasekharam, A. Banthiya, K. Bhanuprakash, A. Petrou and A. G. Coutsolelos, Org. Electron., 2014, 15, 1324-1337.

24 J. N. Clifford, A. Forneli, H.-J. Chen, T. Torres, S.-T. Tan and E. Palomares, J. Mater. Chem., 2011, 21, 1693-1696.

25 L.-Y. Han, A. Islam, H. Chen, C. Malapaka, B. Chiranjeevi, S.-F. Zhang, X.-D. Yang and M. Yanagida, Energy Environ. Sci., 2012, 5, 6057-6066.

26 J. J. Cid, J. H. Yum, S. R. Jang, M. K. Nazeeruddin, E. Martínez-Ferrero, E. Palomares, J. Ko, M. Grätzel and T. Torres, Angew. Chem., Int. Ed., 2007, 46, 8358-8362.

27 M. Kimura, H. Nomoto, N. Masaki and S. Mori, Angew. Chem., Int. Ed., 2012, 51, 4371-4374.

28 H.-P. Wu, Z.-W. Ou, T.-Y. Pan, C.-M. Lan, W.-K. Huang, H.-W. Lee, N. M. Reddy, C.-T. Chen, W.-S. Chao, C.-Y. Yeh and E. W.-G. Diau, Energy Environ. Sci., 2012, 5, 9843-9848.

29 R. Y. Ogura, S. Nakane, M. Morooka, M. Orihashi, Y. Suzuki and K. Noda, Appl. Phys. Lett., 2009, 94, 073308-073310.

30 S. Chang, H.-D. Wang, L. T. L. Lee, S.-Z. Zheng, Q. Li, K.-Y. Wong, W.-K. Wong, X.-J. Zhu, W.-Y. Wong, X.-D. Xiao and T. Chen, J. Mater. Chem. C, 2014, 2, 3521-3526.

31 M. M. Foroushani, H. Dehghani and N. S. Vanani, Electrochim. Acta, 2013, 92, 315-322.

32 Y.-J. Chen, Y.-C. Chang, L.-Y. Lin, W.-C. Chang and S.-M. Chang, Electrochim. Acta, 2015, 178, 414-419.

33 L.-Y. Lin, M. H. Yeh, C.-P. Lee, J. Chang, A. Baheti, R. Vittal, K. R. J. Thomas and K.-C. Ho, J. Power Sources, 2014, 247, 906-914.
34 A. Yella, H.-W. Lee, H. N. Tsao, C.-Y. Yi, A. K. Chandiran, M. K. Nazeeruddin, E. W.-G. Diau, C.-Y. Yeh, S. M. Zakeeruddin and M. Grätzel, Science, 2011, 334, 629634.

35 K. M. Lee, Y. C. Hsu, M. Ikegami, T. Miyasaka, K. R. J. Thomas, J.-T. Lin and K.-C. Ho, J. Power Sources, 2011, 196, 2416-2421.

36 L.-J. Yu, K. Fan, T.-N. Duan, X.-G. Chen, R.-J. Li and T.-Y. Peng, ACS Sustainable Chem. Eng., 2014, 2, 718-725.

37 J.-C. Liu, B. Liu, Y.-Y. Tang, W.-W. Zhang, W.-J. Wu, Y.-S. Xie and W.-H. Zhu, J. Mater. Chem. C, 2015, 3, 11144-11150.

38 S.-H. Fan, X.-F. Lu, H. Sun, G. Zhou, Y.-J. Chang and Z.-S. Wang, Phys. Chem. Chem. Phys., 2016, 18, 932-938.

39 K. Pei, Y.-Z. Wu, H. Li, Z.-Y. Geng, H. Tian and W.-H. Zhu, ACS Appl. Mater. Interfaces, 2015, 7, 5296-5304.

40 L.-H. Dong, Z.-W. Zheng, Y.-F. Wang, X. Li, J.-L. Hua and A.-G. Hu, J. Mater. Chem. A, 2015, 3, 11607-11614.

41 S.-Q. Fan, C. Kim, B.-Z. Fang, K.-X. Liao, G.-J. Yang, C.-J. Li, J.-J. Kim and J. Ko, J. Phys. Chem. C, 2011, 115, 7747-7754.

42 L. H. Nguyen, H. K. Mulmudi, D. Sabba, S. A. Kulkarni, S. K. Batabyal and K. Nonomura, Phys. Chem. Chem. Phys., 2012, 14, 16182-16186.

43 G. D. Sharma, S. P. Singh, R. Kurchaniac and R. J. Balld, RSC Adv., 2013, 3, 6036-6043.

44 S.-B. Zhu, Z.-W. An, X. Sun, Z.-S. Wu, X.-B. Chen and P. Chen, Dyes Pigm., 2015, 120, 85-92.

45 C.-M. Lan, H.-P. Wu, T.-Y. Pan, C.-W. Chang, W.-S. Chao, C.-T. Chen, C.-L. Wang, C.-Y. Lin and E. W.-G. Diau, Energy Environ. Sci., 2012, 5, 6460-6464.

46 H.-N. Tian, X.-C. Yang, R.-K. Chen, R. Zhang, A. Hagfeldt and L.-C. Sun, J. Phys. Chem. C, 2008, 112, 11023-11033.

47 A. Hagfeldt and M. Grätzel, Acc. Chem. Res., 2000, 33, 269277.

48 D.-R. Cao, J.-N. Peng, Y.-P. Hong, X.-M. Fang, L.-Y. Wang and H. Meier, Org. Lett., 2011, 13, 1610-1613.

49 Y.-P. Hong, J.-Y. Liao, D.-R. Cao, X.-F. Zang, D.-B. Kuang, L.-Y. Wang, H. Meier and C.-Y. Su, J. Org. Chem., 2011, 76, 8015-8021.

50 K. E. Lee, M. A. Gomez, S. Elouatik and G. P. Demopoulos, Langmuir, 2010, 26, 9575-9583.

51 G. D. Sharma, P. A. Angaridis, S. Pipou, G. E. Zervaki, V. Nikolaou, R. Misra and A. G. Coutsolelos, Org. Electron., 2015, 25, 295-307.

52 F. D. Angelis, S. Fantacci, A. Selloni, M. Grätzel and M. K. Nazeeruddin, Nano Lett., 2007, 7, 3189-3195.

53 F.-T. Lu, J. Zhang, Y.-Z. Zhou, Y.-M. Zhao, B. Zhang and Y.-Q. Feng, Dyes Pigm., 2016, 125, 116-123.

54 J.-H. Yum, S.-R. Jang, P. Walter, T. Geiger, F. Nüesch, S. Kim, J. Ko, M. Grätzel and M. K. Nazeeruddin, Chem. Commun., 2007, 44, 4680-4682.

55 K. Lee, S. Park, M. J. Ko, K. Kim and N. G. Park, Nat. Mater., 2009, 8, 665-671.

56 Z.-Q. Wan, C.-Y. Jia, Y.-D. Duan, L.-L. Zhou, Y. Lin and Y. Shi, J. Mater. Chem., 2012, 22, 25140-25147.

57 J. Bisquert, A. Zaban, M. Greenshtein and I. Mora-Sero, J. Am. Chem. Soc., 2004, 126, 13550-13559. 